\title{
Techniques in Subsurface Mapping using Spectral Decomposition and Well Log Character: Case Study of Cenozoic Fluvial \& Marginal Marine Reservoirs of Llanos Foothills, Colombia
}

Southeastern Section - 68th Annual Meeting - 2019

SAEID, Essam, KELLOGG, James N., KENDALL, Christopher, DE KEYSER Thomas, HAFIZ, Ibraheem, ALBESHER, Ziyad and MARTINEZ, Jose Antonio5, 


\section{Techniques in Subsurface Mapping using Spectral Decomposition and Well Log Character}

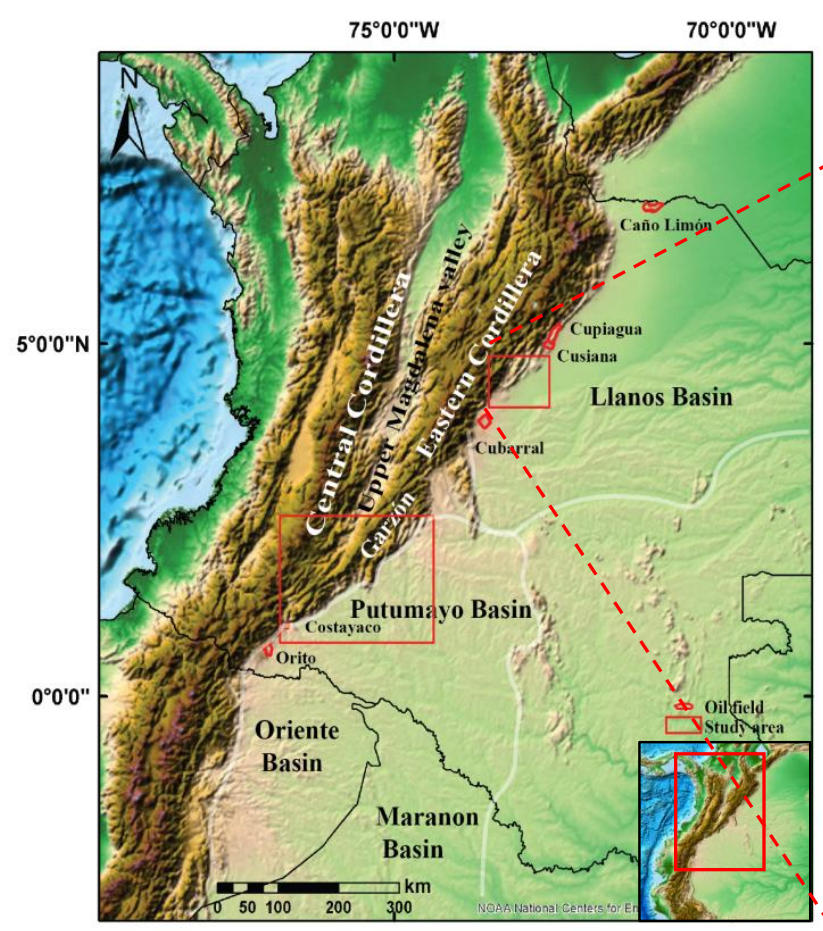

Objective of this study - use spectral decomposition method for subsurface mapping through frequency anomalies

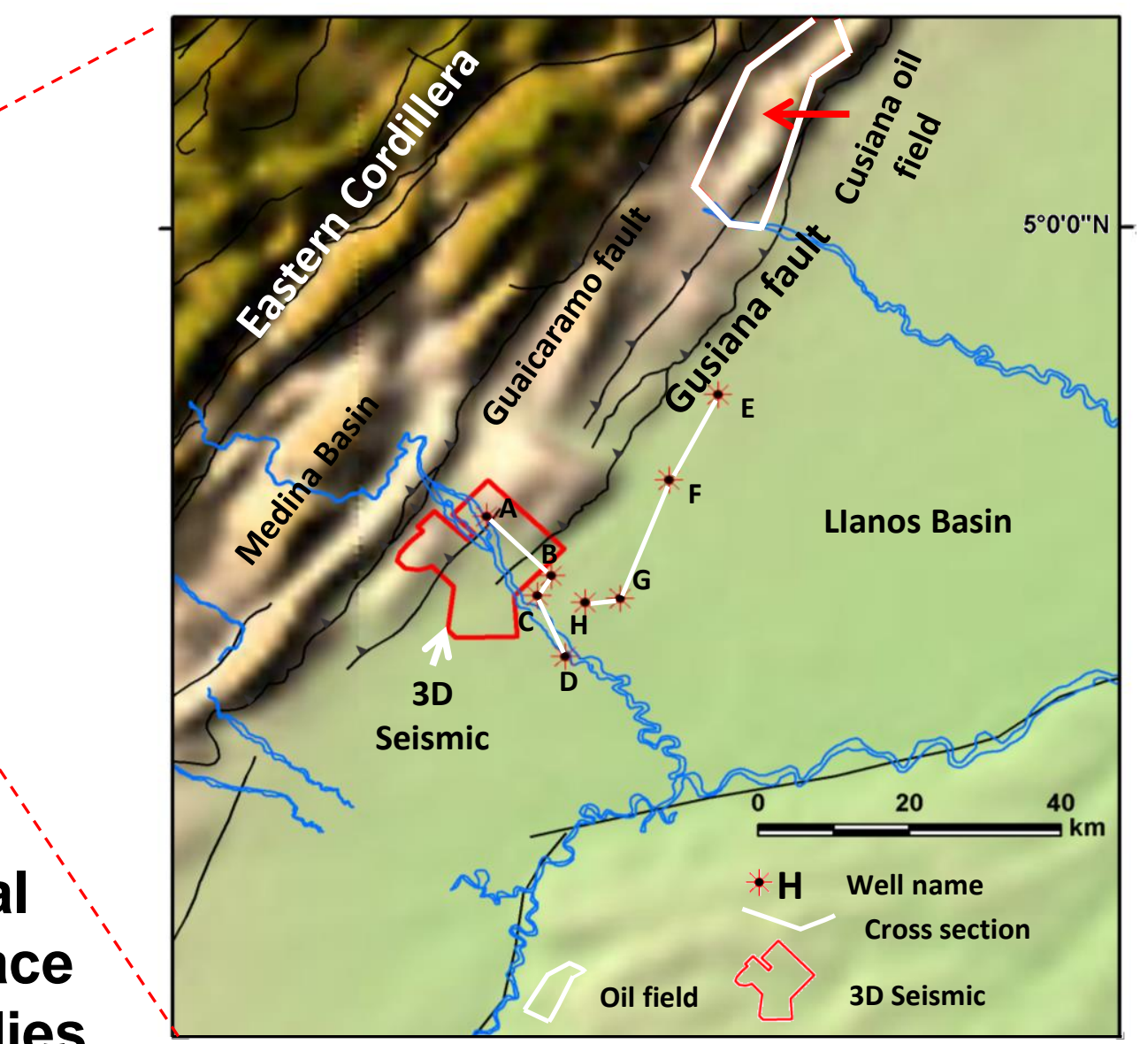
in a geologically and seismically challenging area - Llanos Foothills, Eastern Cordillera, Colombia 
$>$ New techniques of well-to-well correlation

$>$ Spectral Decomposition

$>$ Integration of Well logs and Spectral Decom as subsurface mapping techniques

$>$ Spectral Decom. expression of Tectonic Deformation $>$ Conclusions 


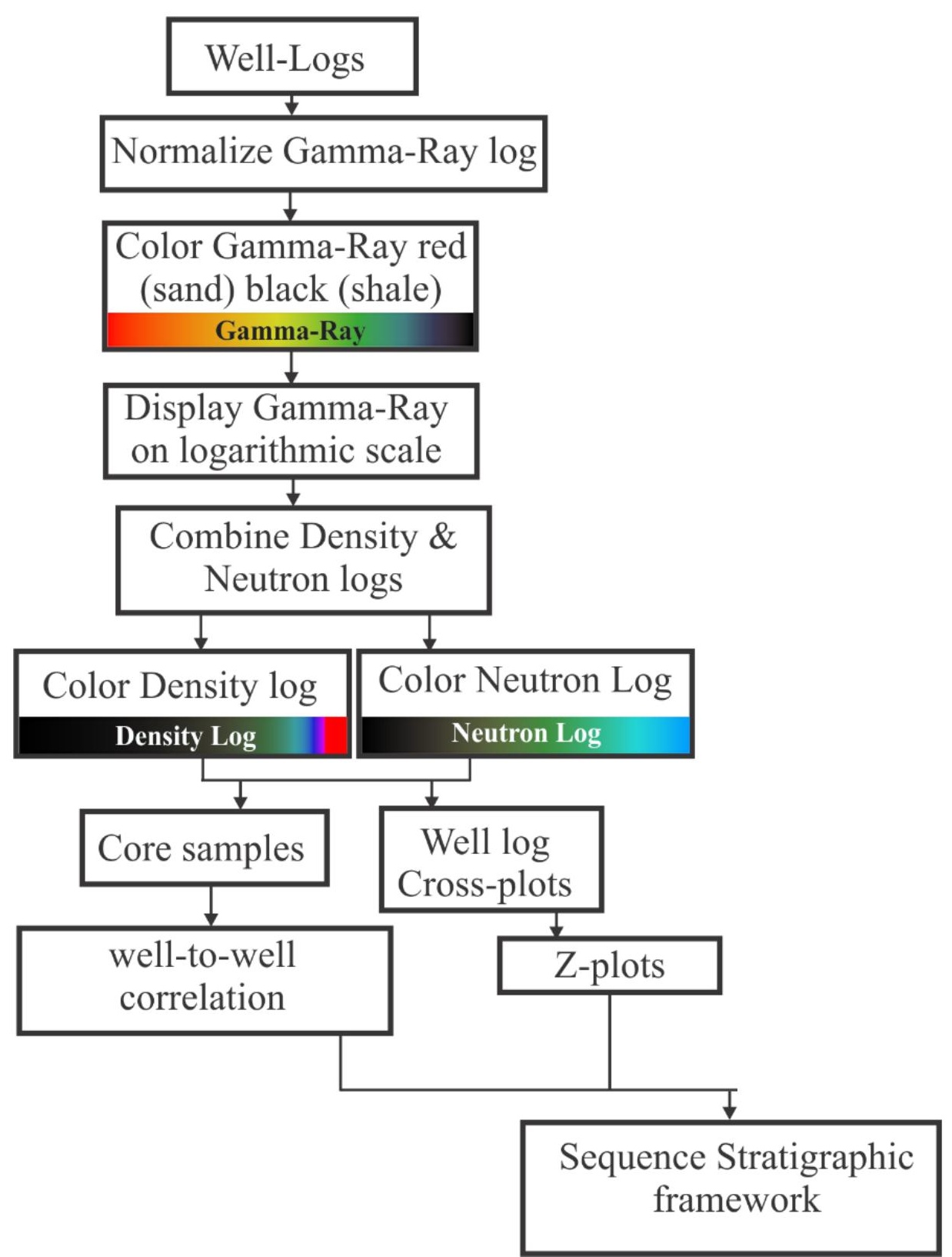




\section{Well Logs Color Scale}

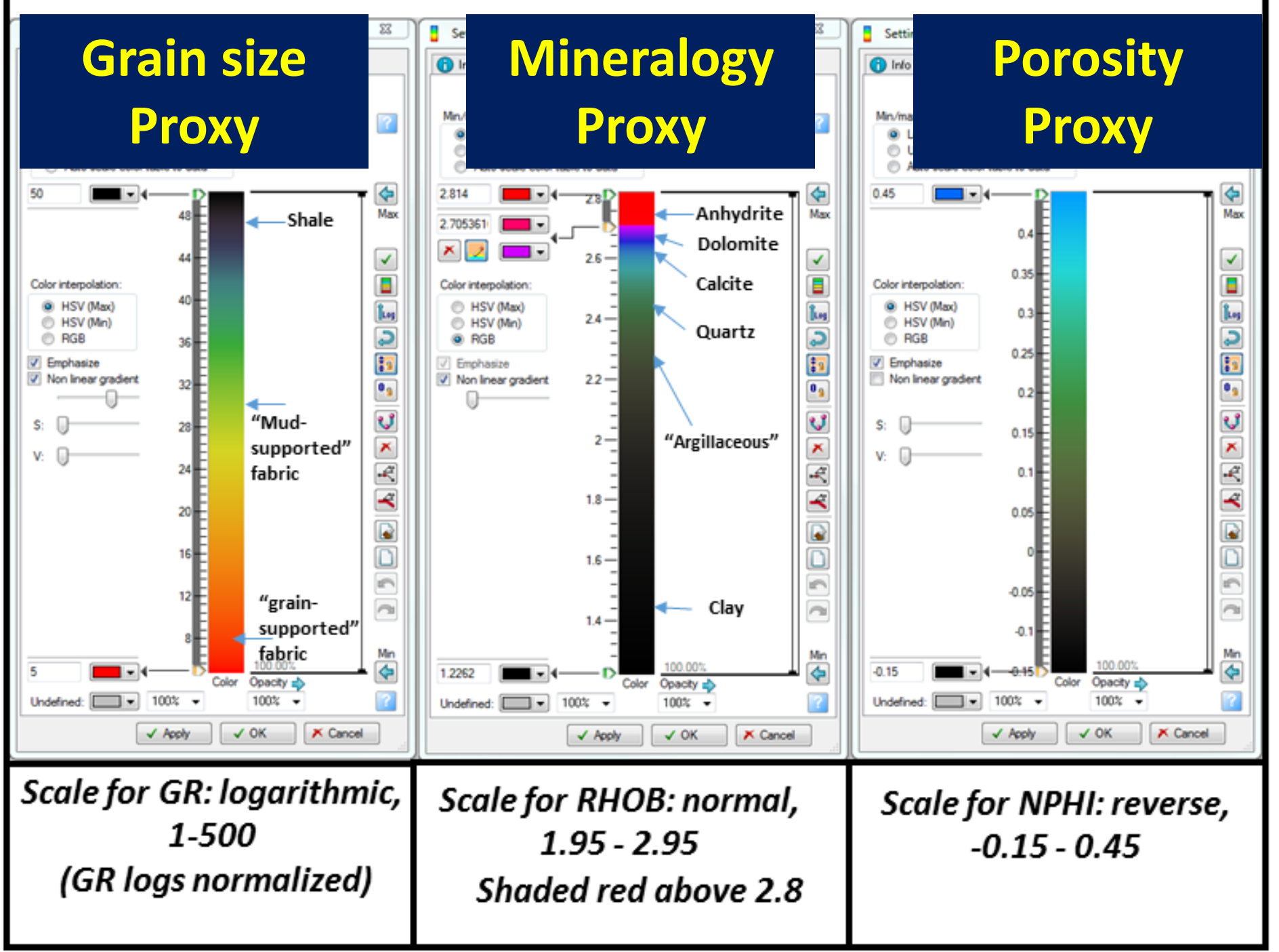




\section{口 Normalized GR \& Display on Log Scale}

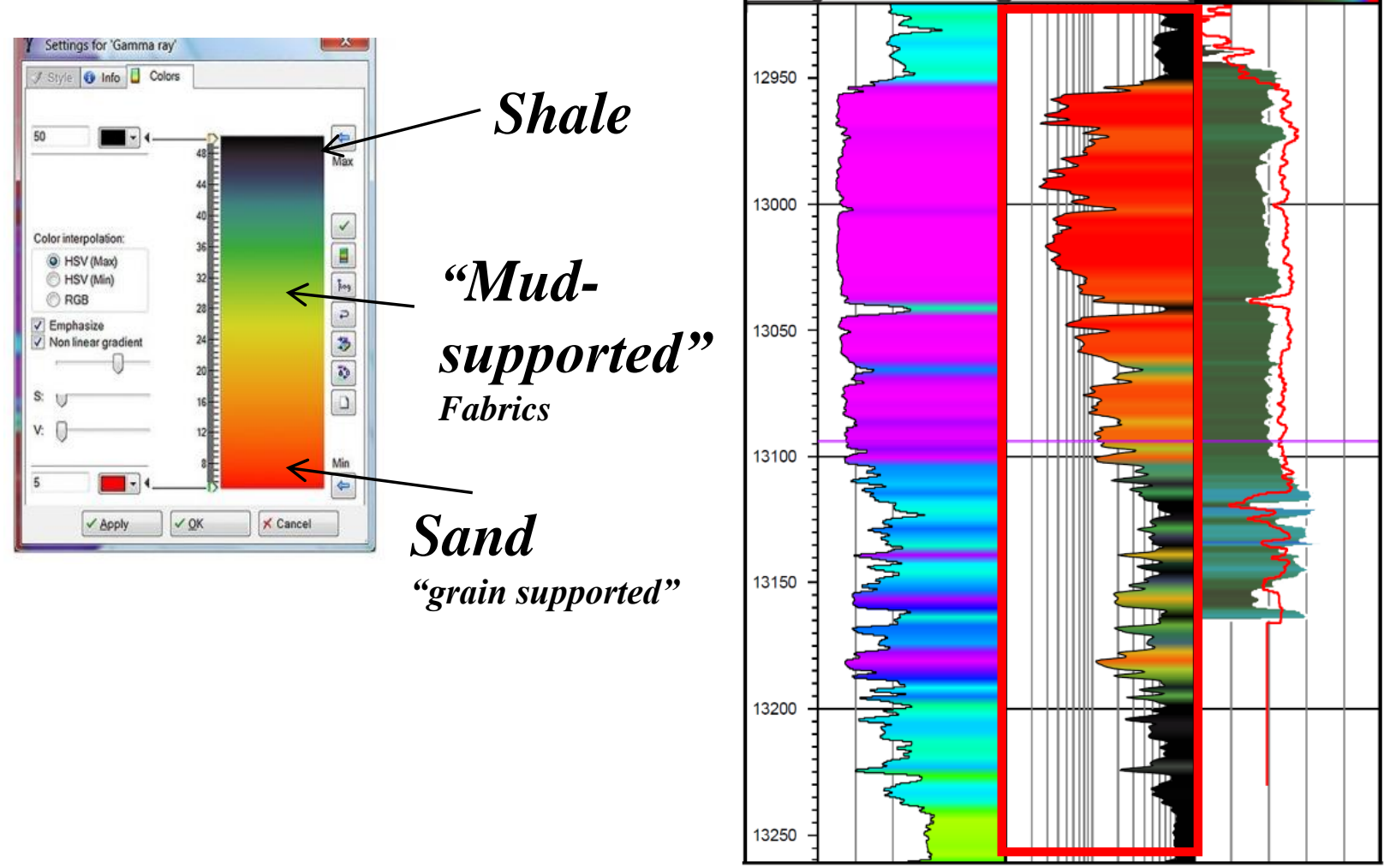

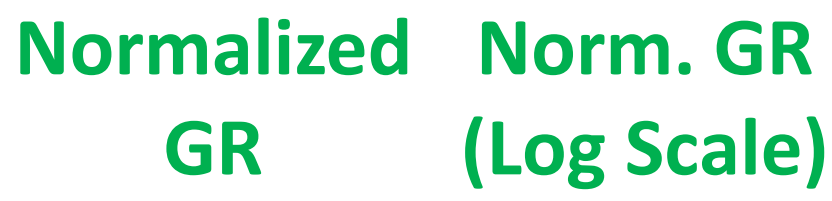

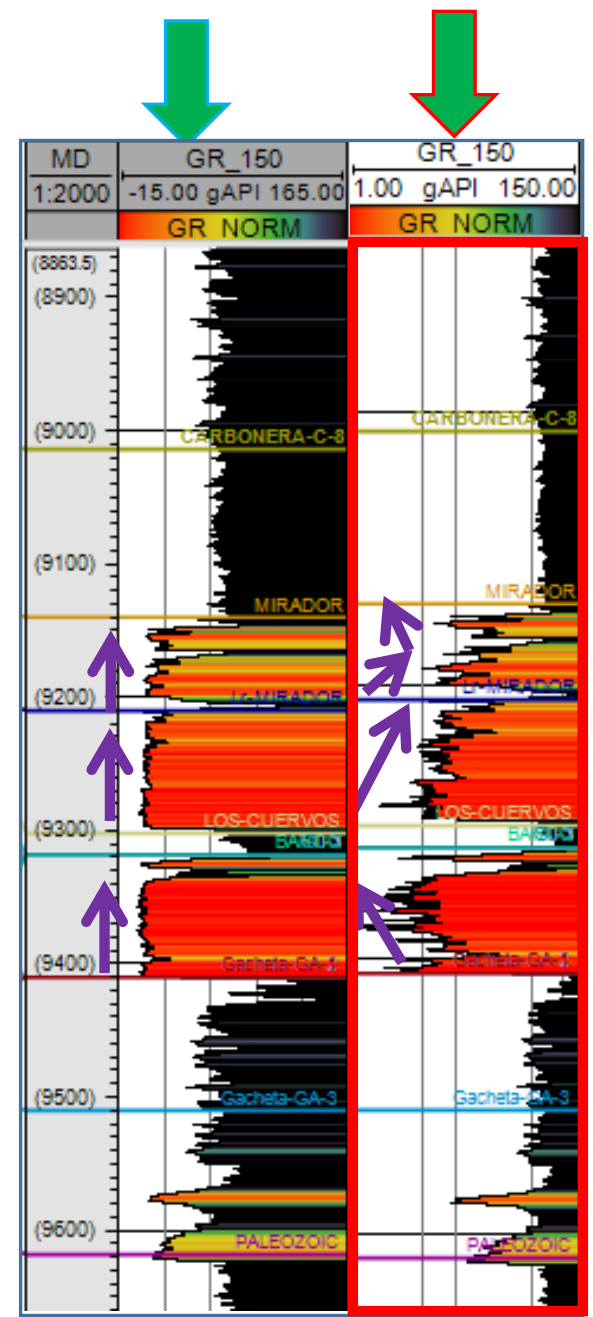




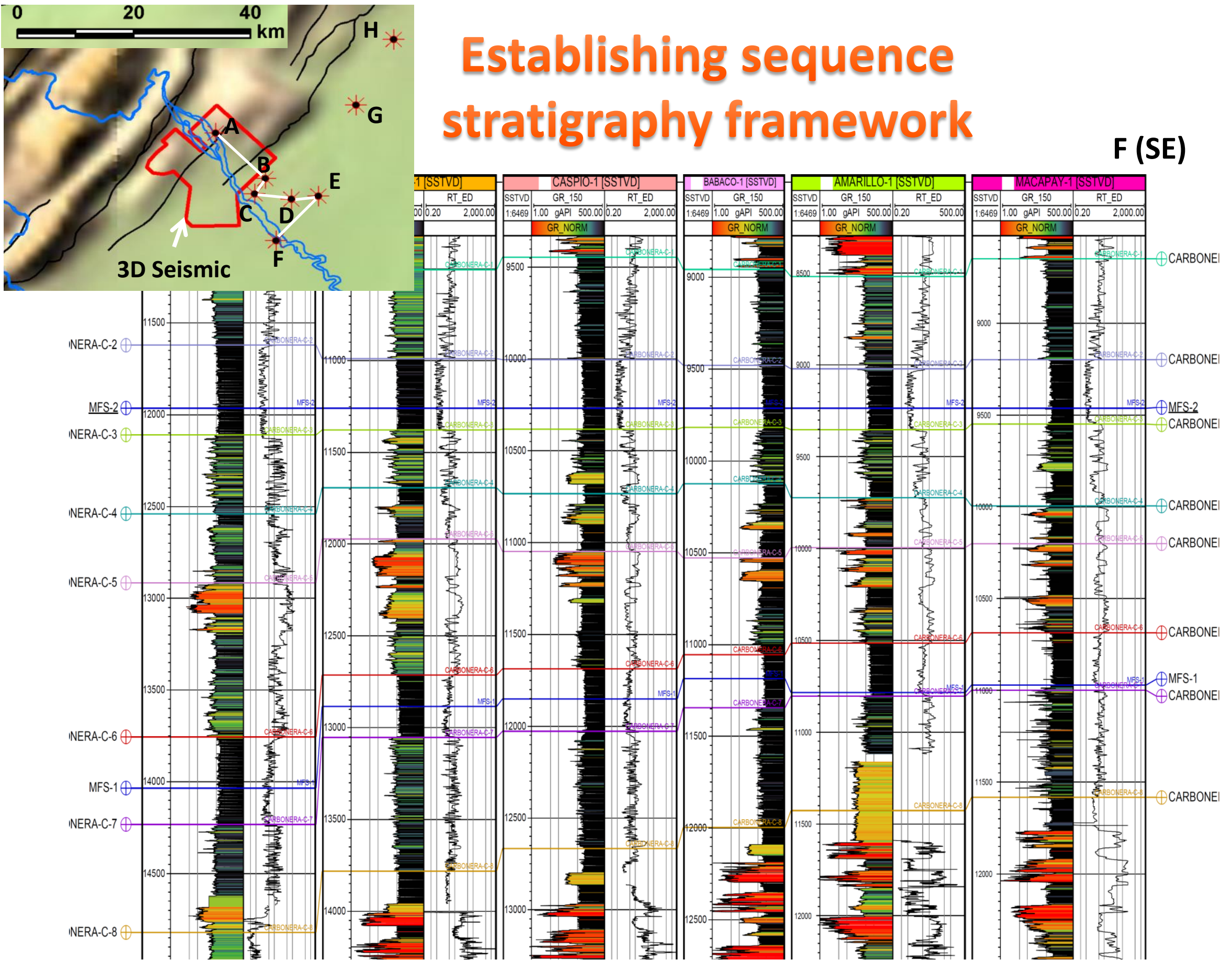




\section{Connecting the potential}

\section{A (NW)}

\section{reservoirs based on well logs}

F (SE)

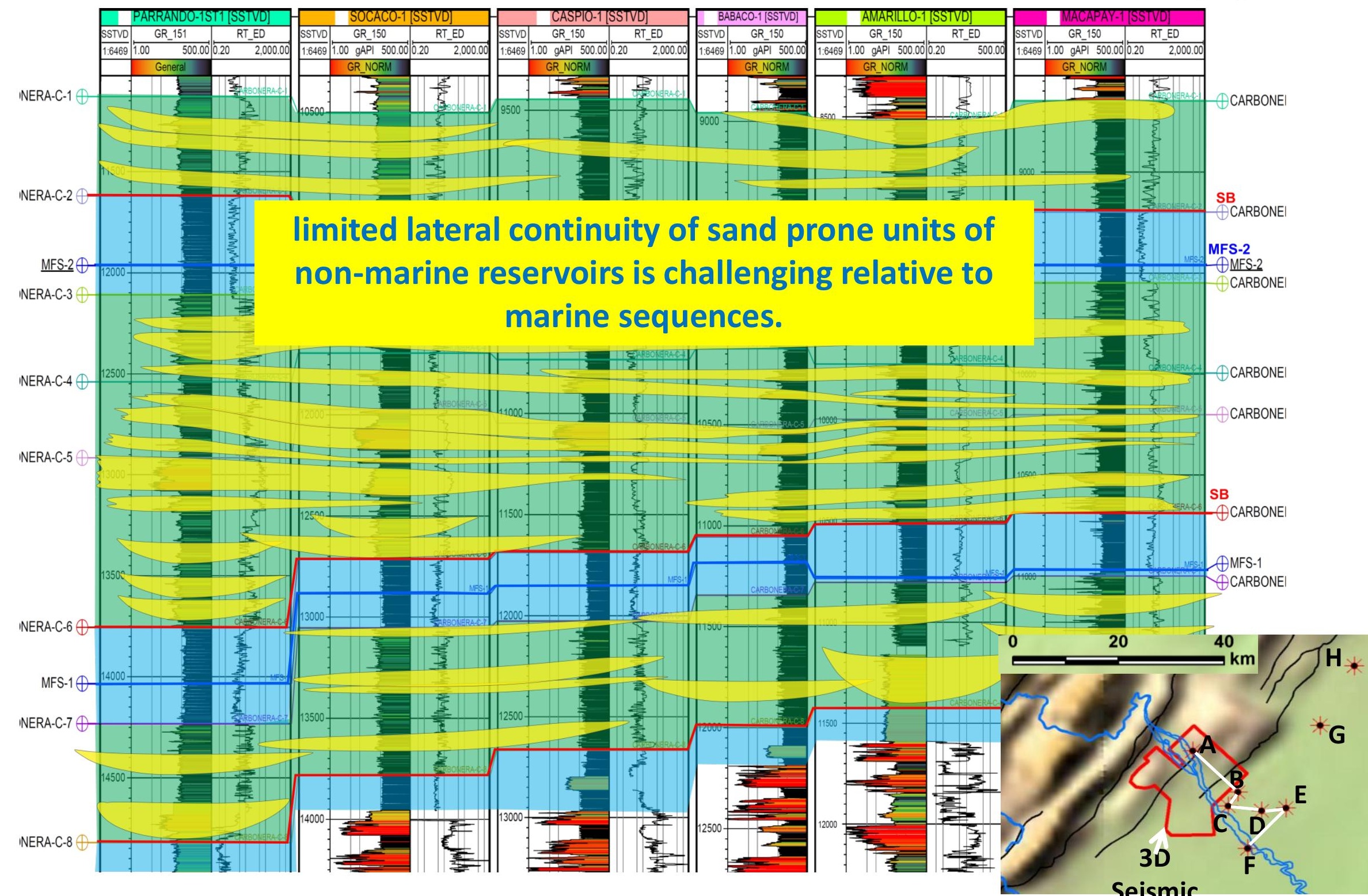


$>$ Well logs and cores can identify fluvial, estuarine and/or deep-water fans.

$>$ It is impossible to predict channel orientation and correlate channels from well logs alone or from 3D seismic.

$>$ My next slide shows 3 different interpretations by three experts interpreting the same geological section displaying fluvial sediments on well logs 


\section{Why this research is important?}

\section{Three interpretations of the} braided-fluvial deposits of the Travis Peak Formation TX.

Tye (1991)

Sandstone connectivity Is the major rule in oil exploration and production

Bridge and (a) Travis Peak Fm., Zone 1, interpretation by Tye (1991)

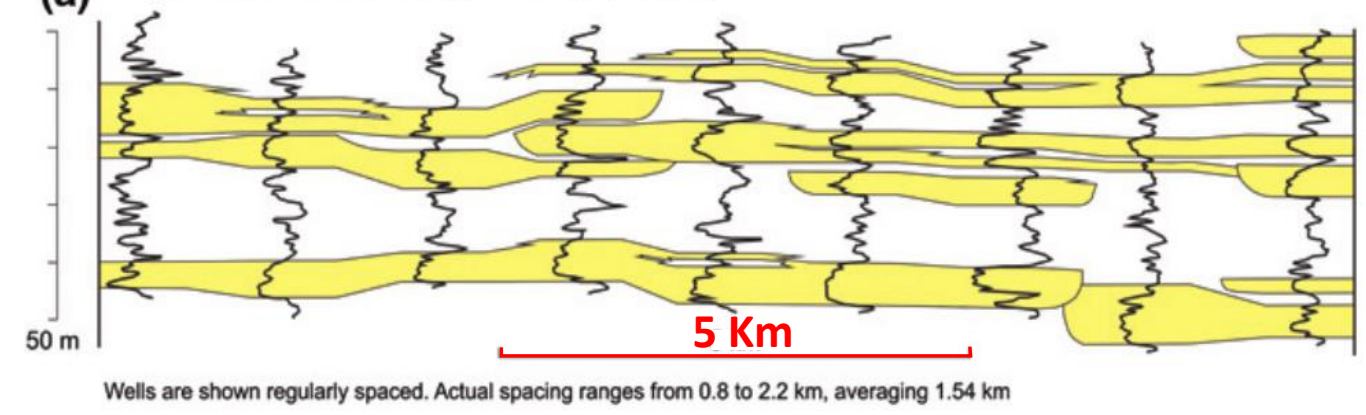

(b) Travis Peak Fm., Zone 1, interpretation by Bridge and Tye (2000) Tye (2000)

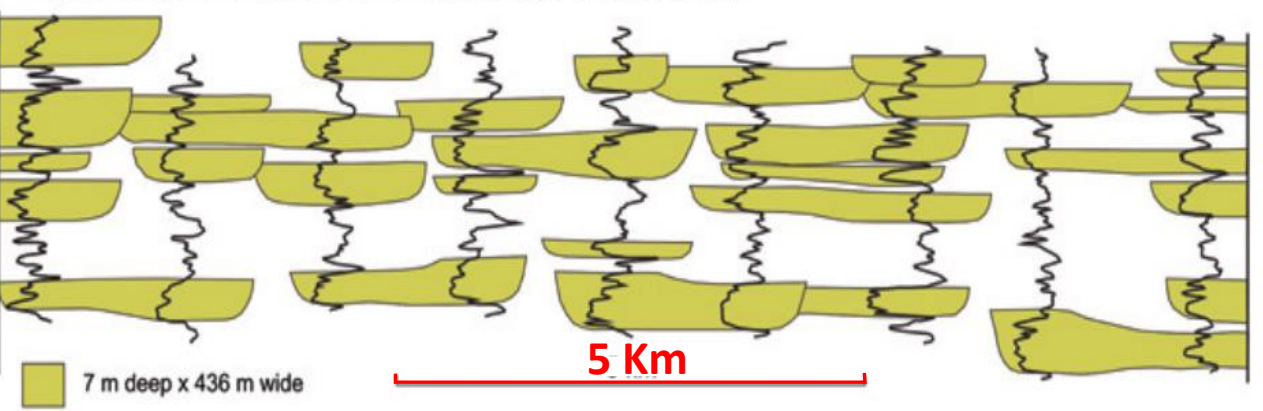

(c) Travis Peak Fm., Zone 1, model based on high sand and minimal relief on channel bounding surfaces

Miall 2006 \& 2014

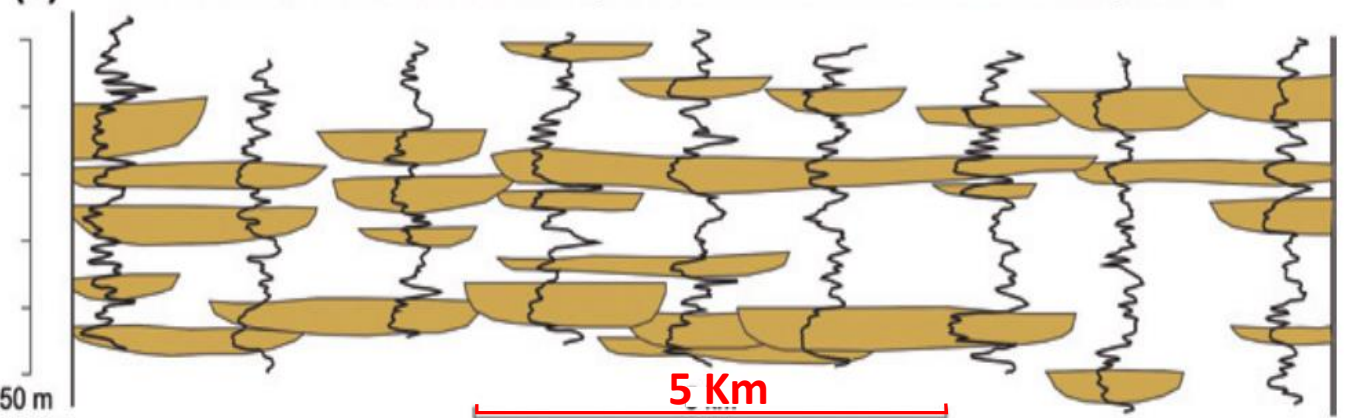


$>$ New techniques of well-to-well correlation $>$ Spectral Decomposition

$>$ Integration of Well logs and Spectral Decom as subsurface mapping techniques

$>$ Spectral Decom. expression of Tectonic Deformation $>$ Conclusions 


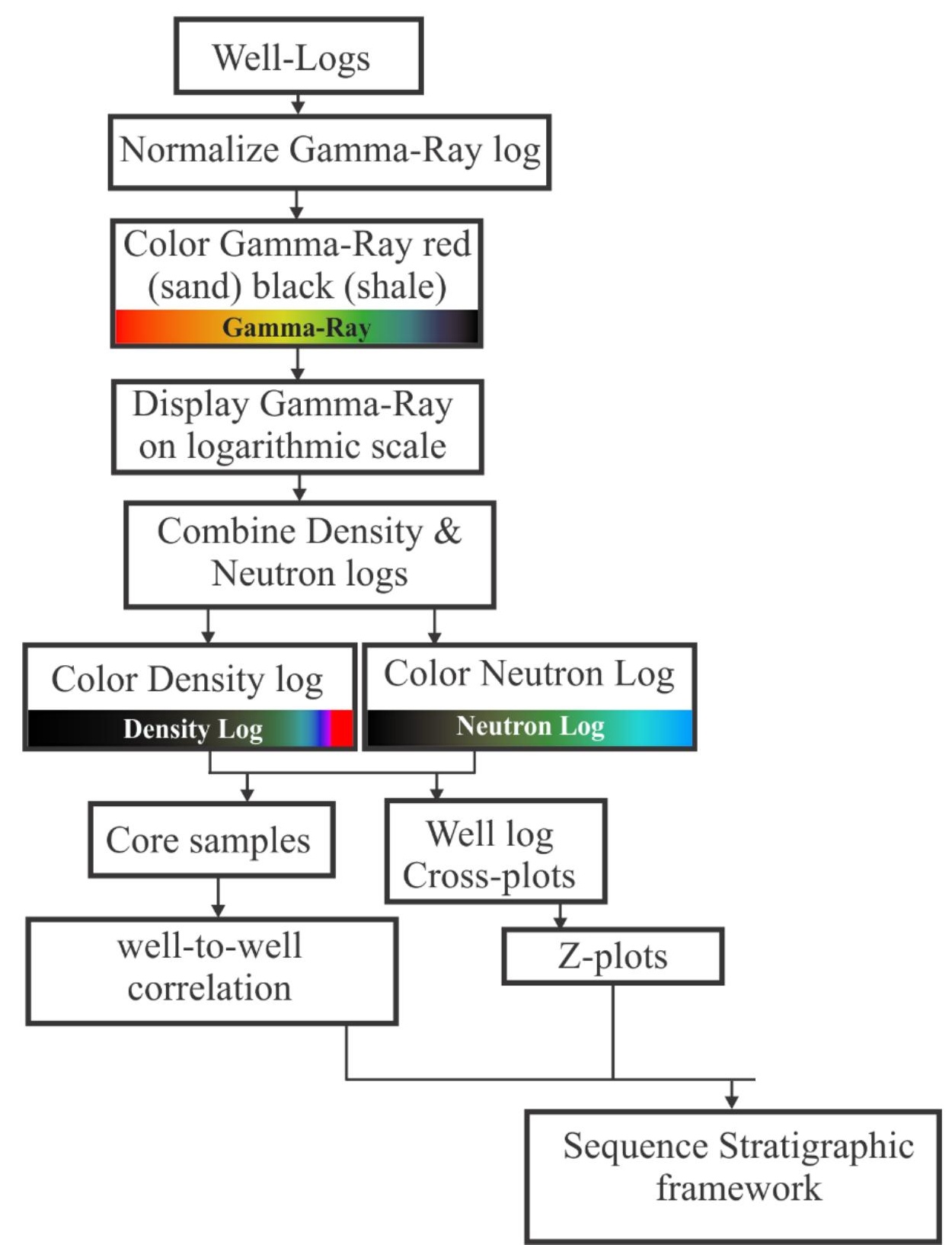




\section{What is Spectral Decomposition?}

-A way of viewing the data contained in discrete sections of the 3D seismic data frequency spectrum
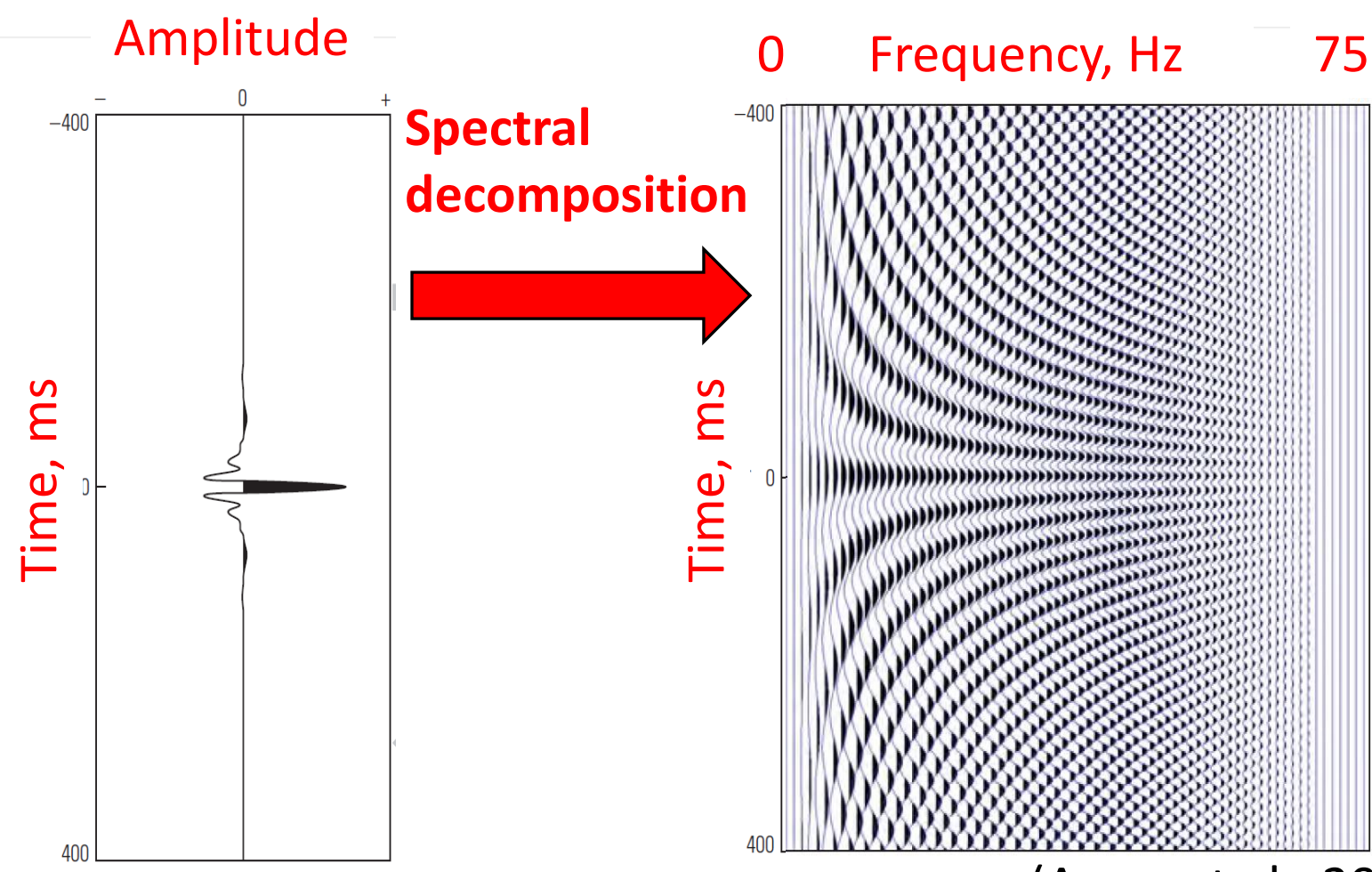

(Aarre et al., 2012) 


\section{Workflow of Spectral Decomposition}

Extract (3) dominant frequencies, break into 3 discrete frequency

volumes and flatten at the horizon of interest

Identify seismic horizons
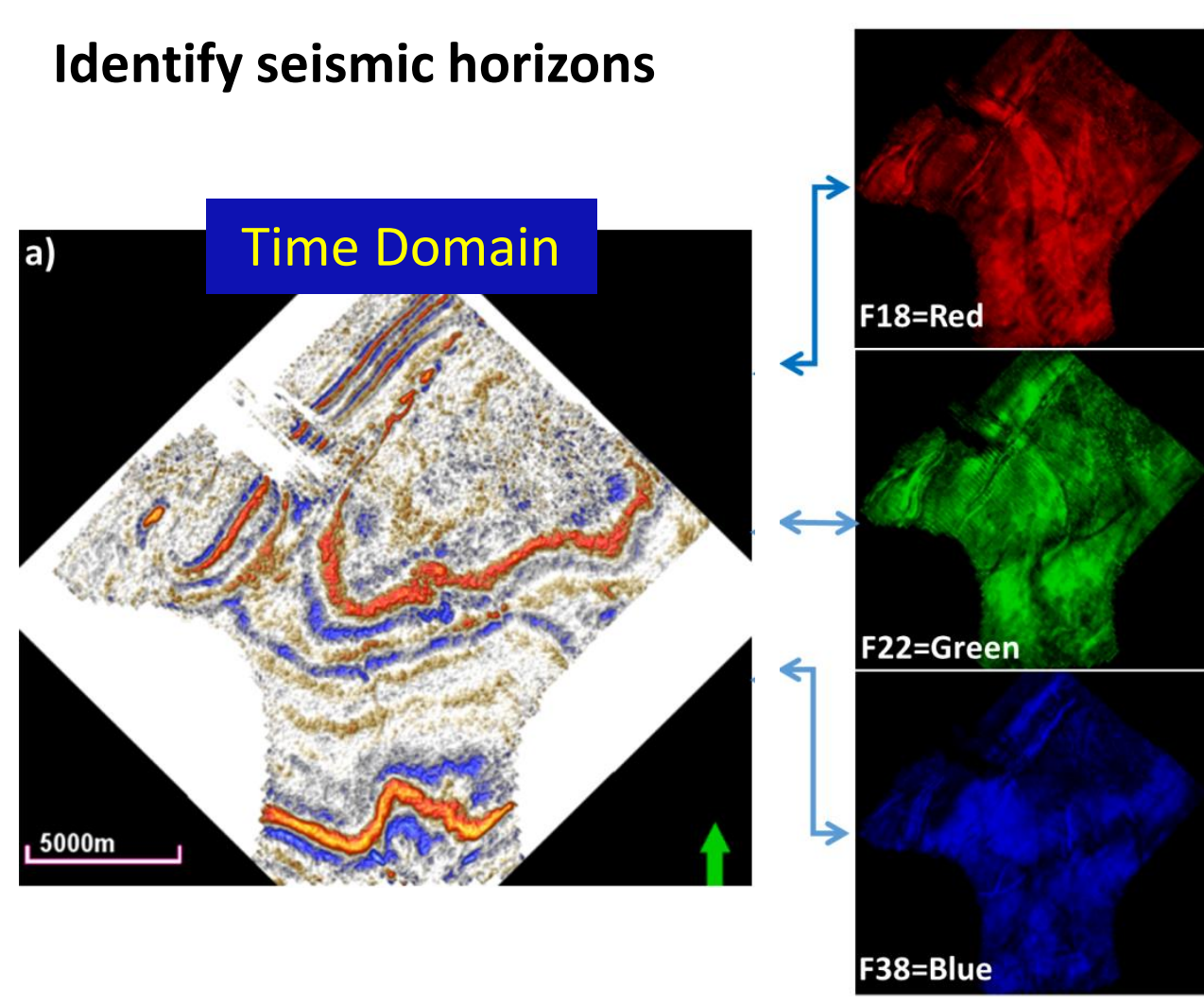

Frequency volume displaying channels within flattened horizons

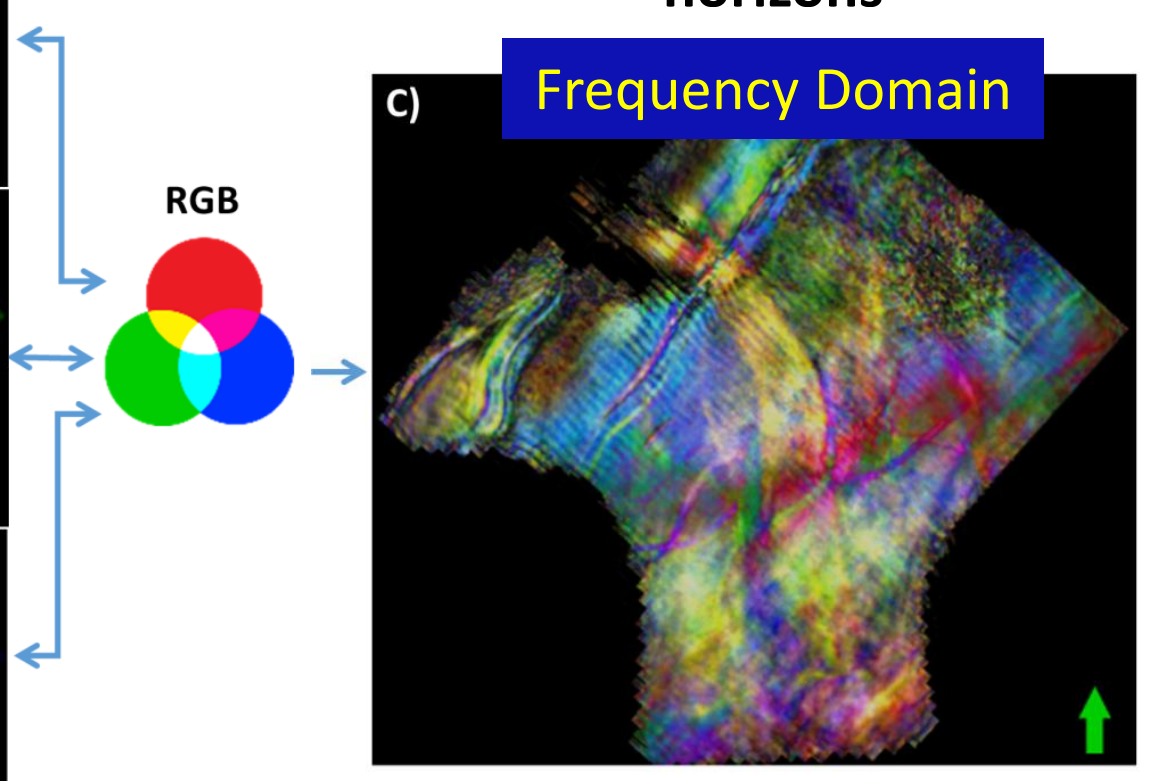

Blend dominant frequencies volumes by RGB mixer 


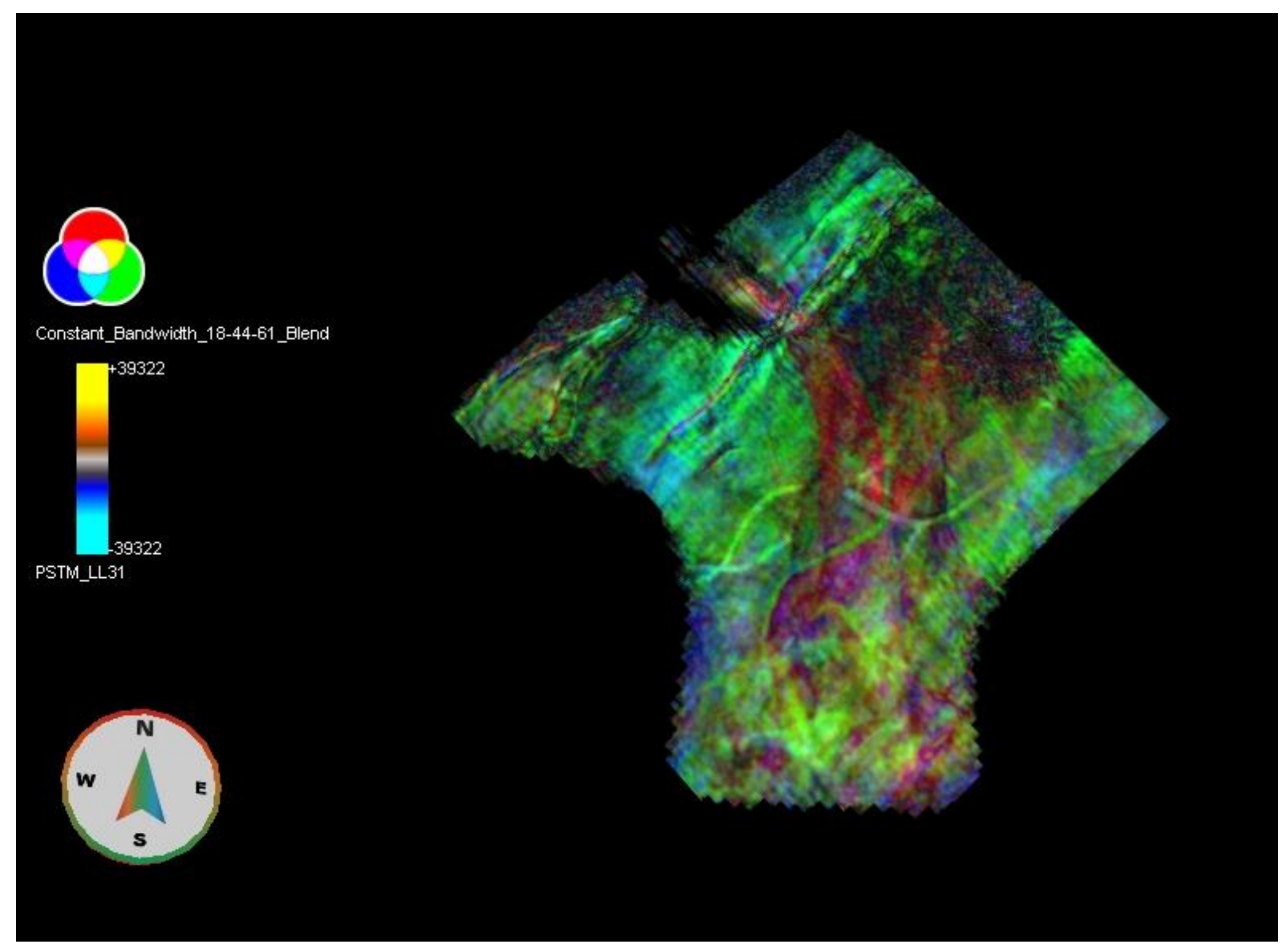




\section{Types of Spectral Decomposition}

1-STFT= Short Time FT 2-CWT= Continuous wavelet

3-MP= Matching pursuit

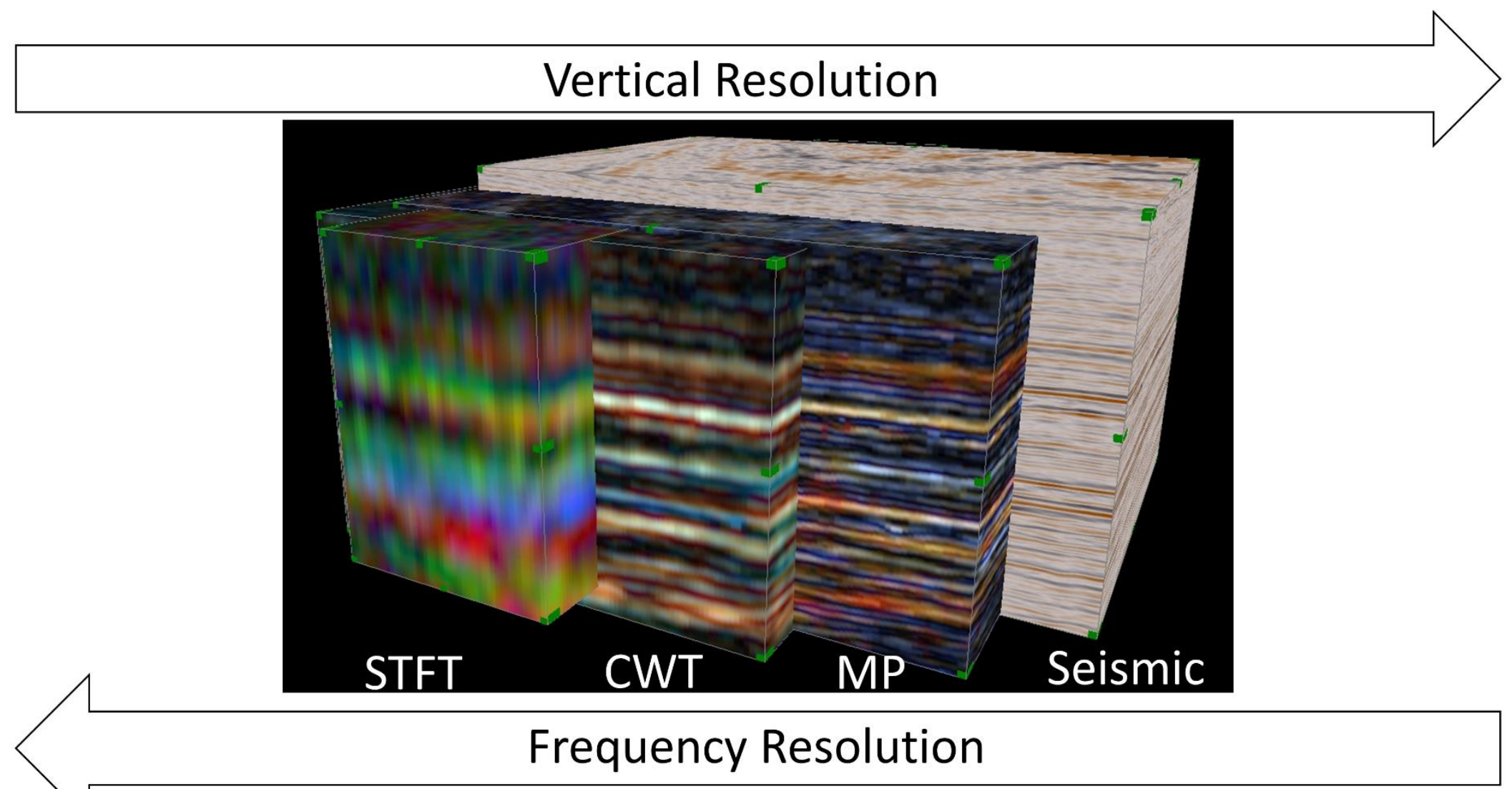




\title{
Spectral Decomposition results similar to modern fluvial analog from Peru
}

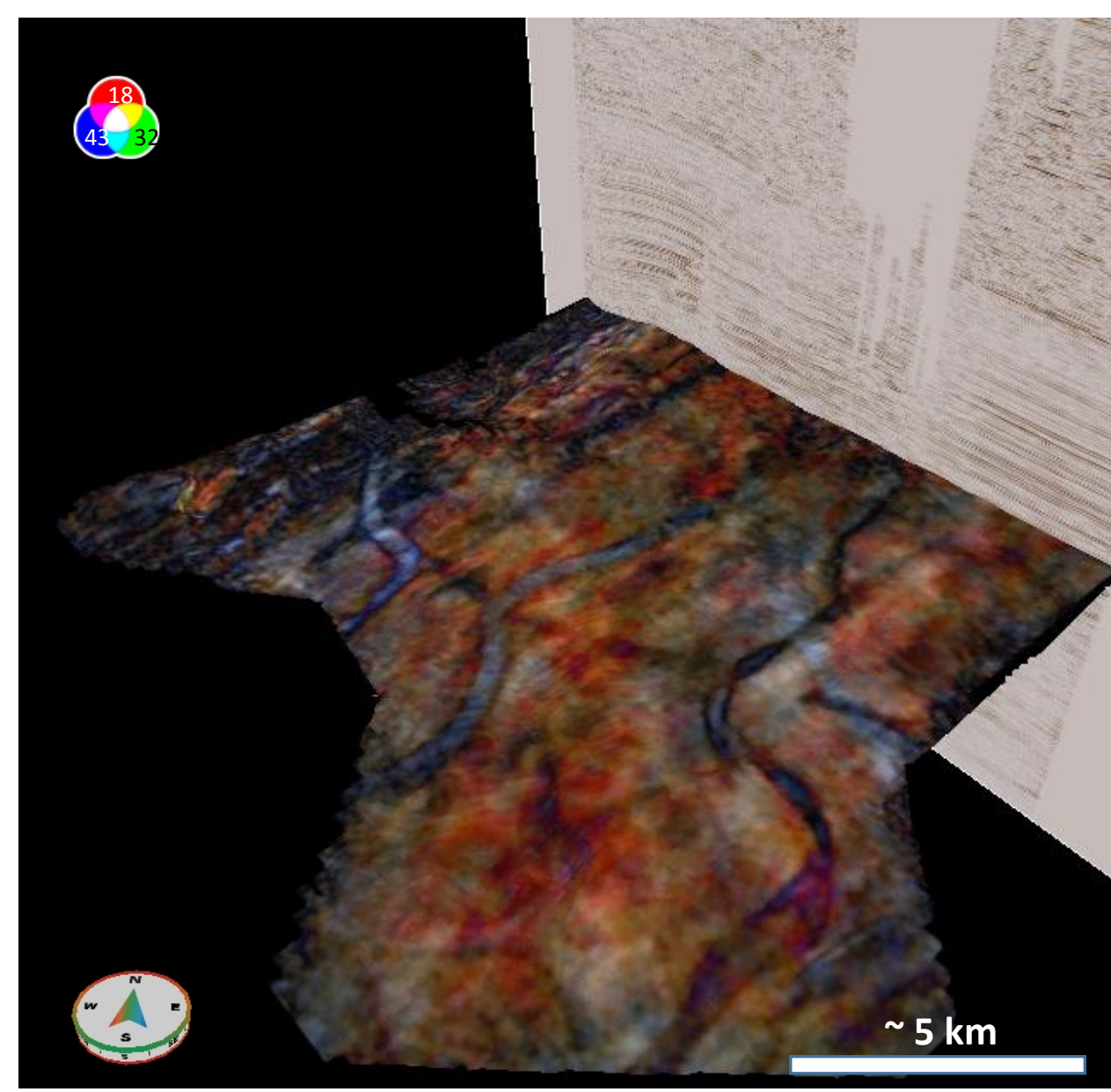

\author{
Ucayali River Peru
}

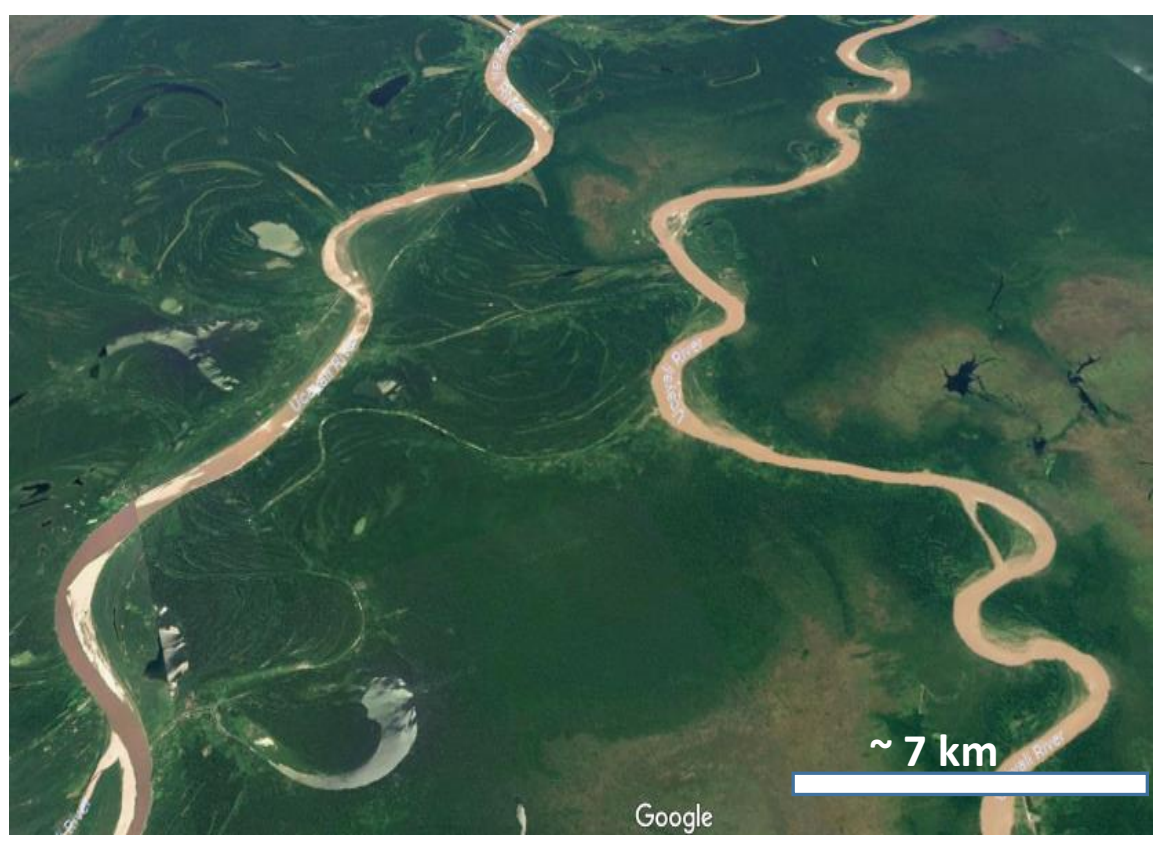


$>$ New techniques of well-to-well correlation

$>$ Spectral Decomposition

$>$ Integration of Well logs and Spectral Decom as subsurface mapping techniques

$>$ Spectral Decom. expression of Tectonic Deformation

$>$ Conclusions 


\section{Connecting the potential}

\section{A (NW)}

\section{reservoirs based on well logs}

F (SE)

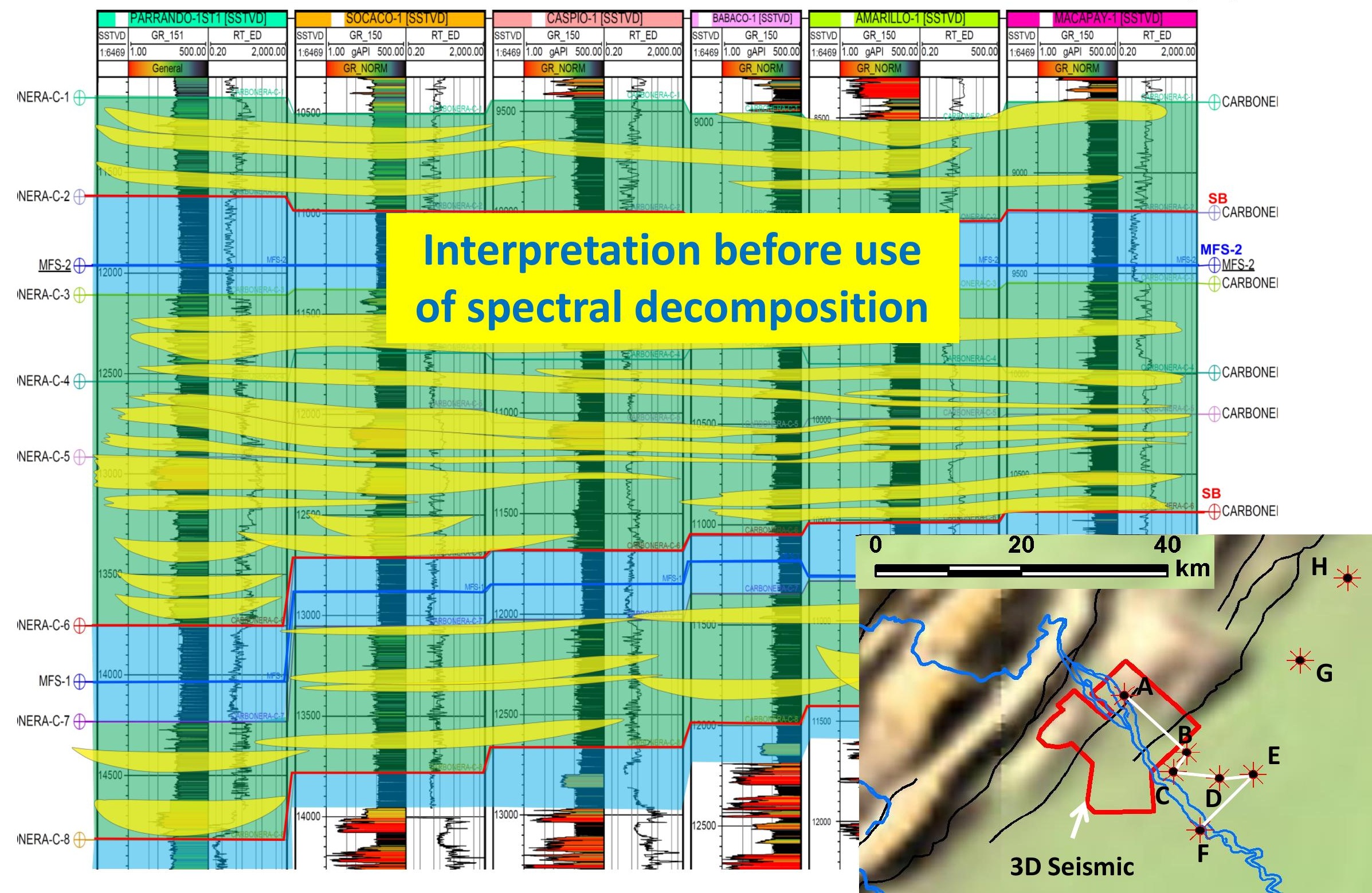




\section{Connecting potential reservoirs based on}

\section{$A(N W)$}

spectral Decomposition

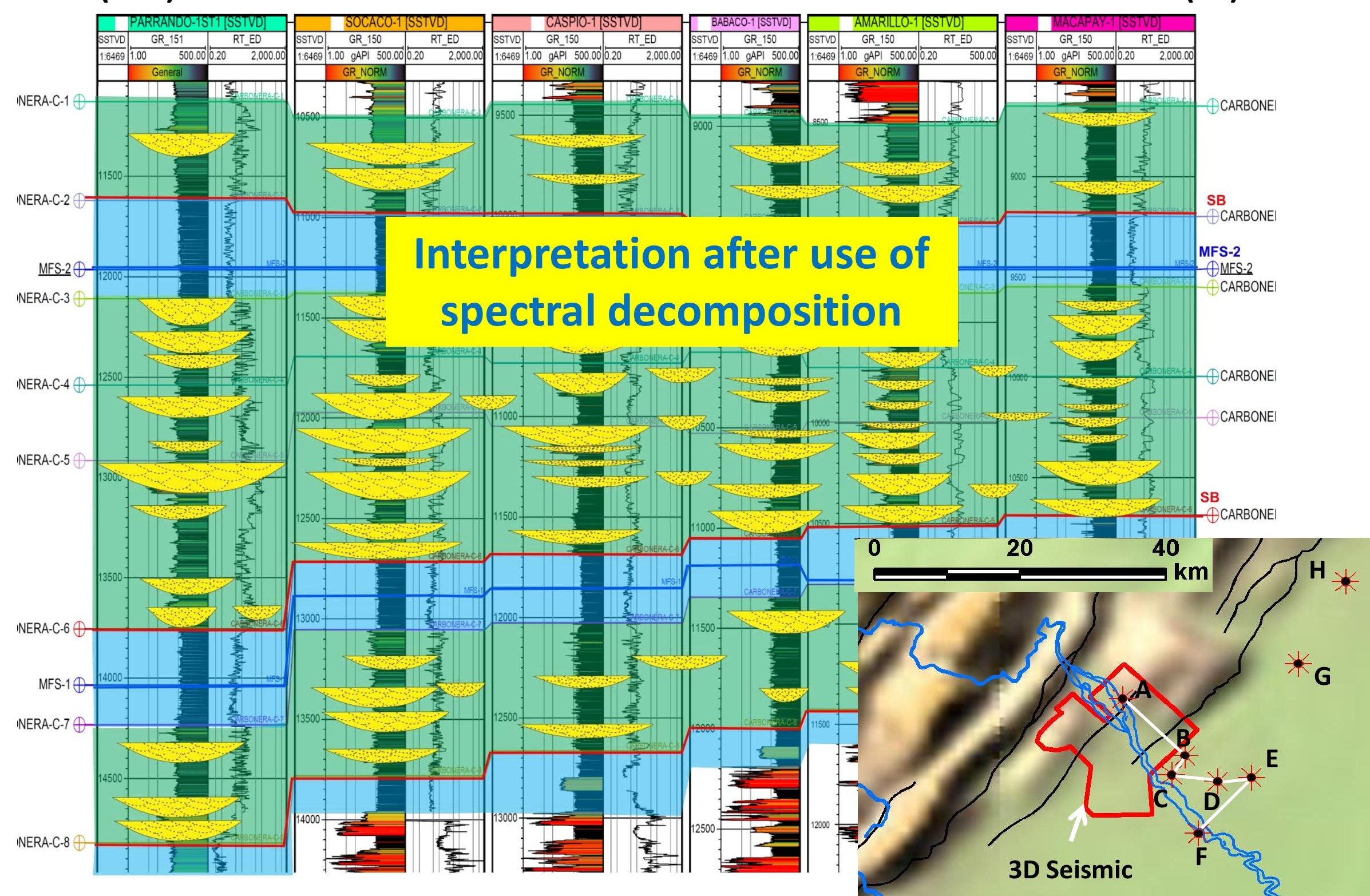


$>$ New techniques of well-to-well correlation $>$ Spectral Decomposition

$>$ Integration of Well logs and Spectral Decom as subsurface mapping techniques

$>$ Spectral Decom. expression of Tectonic Deformation

$>$ Conclusions 


\section{Spectral Decomposition Expression of Tectonic Deformation}

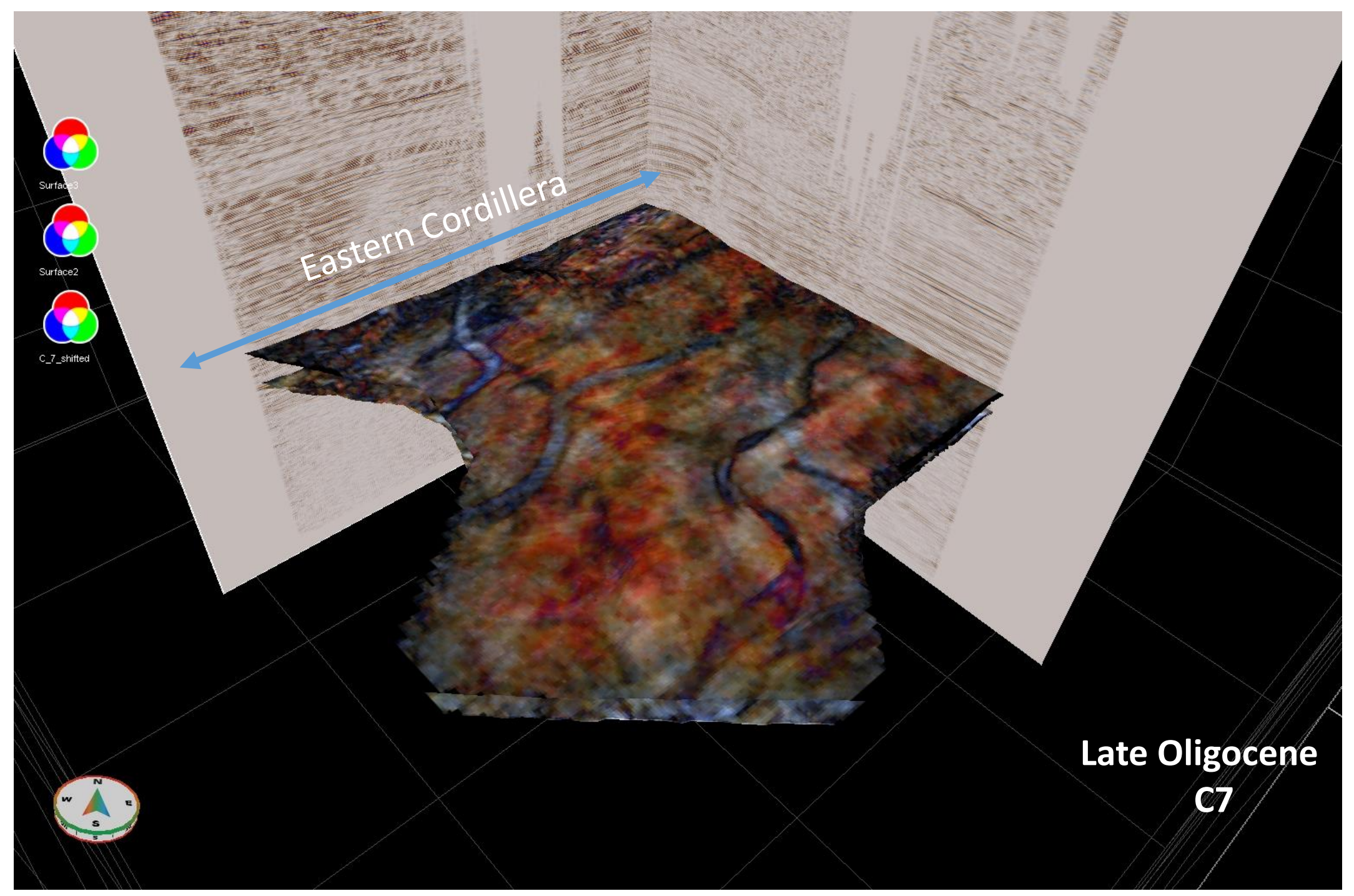


Conceptual model of fluvial drainage versus tectonic

\section{structure and regional slope}

\section{A. Early rift inversion}

\begin{tabular}{|l|}
\hline $\begin{array}{l}\text { low structural relief } \\
\text { gentle regional slope }\end{array}$ \\
\hline
\end{tabular}

longitudinal-dominated streams

(structure-controlled)

\section{Late Oligocene (Carbonera C7)}

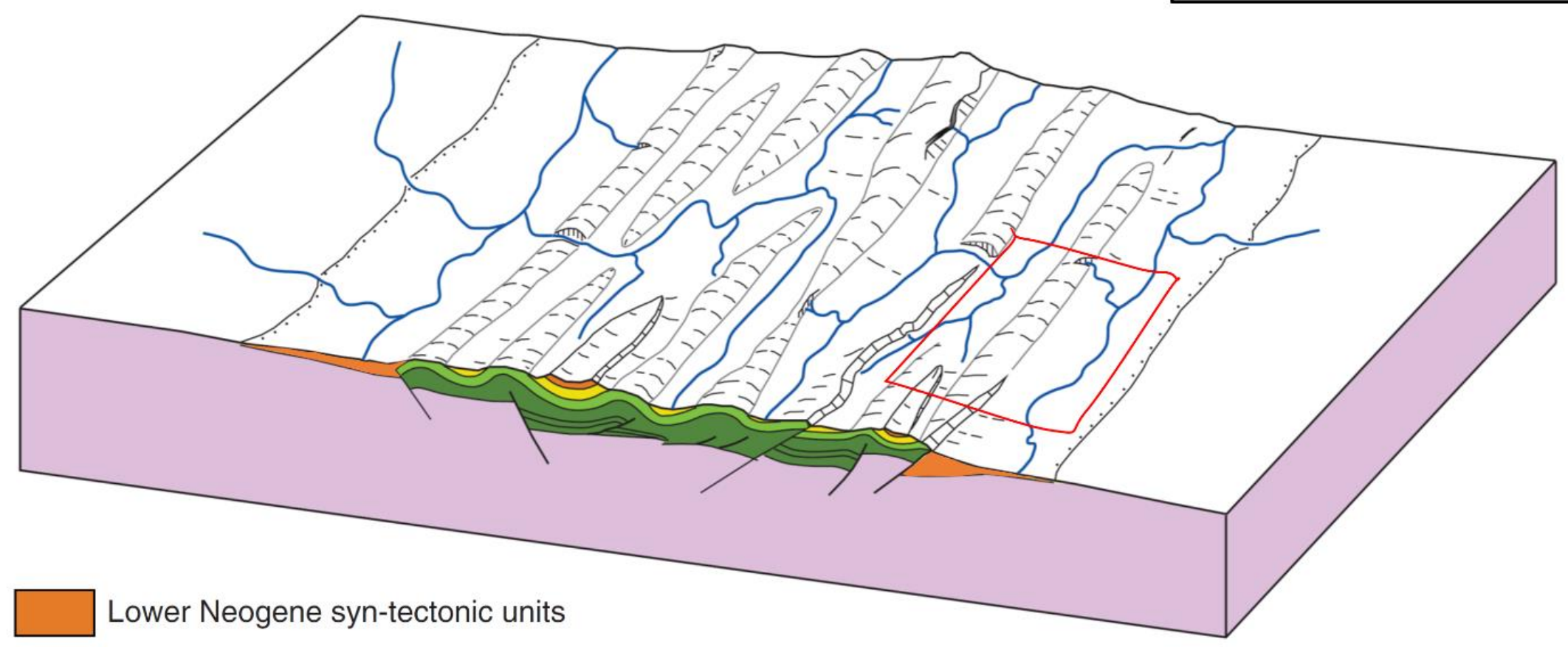

$\square$ Paleogene units

Upper Cretaceous postrift units

Lower Cretaceous synrift units 


\section{Spectral Decomposition Expression of Tectonic Deformation}

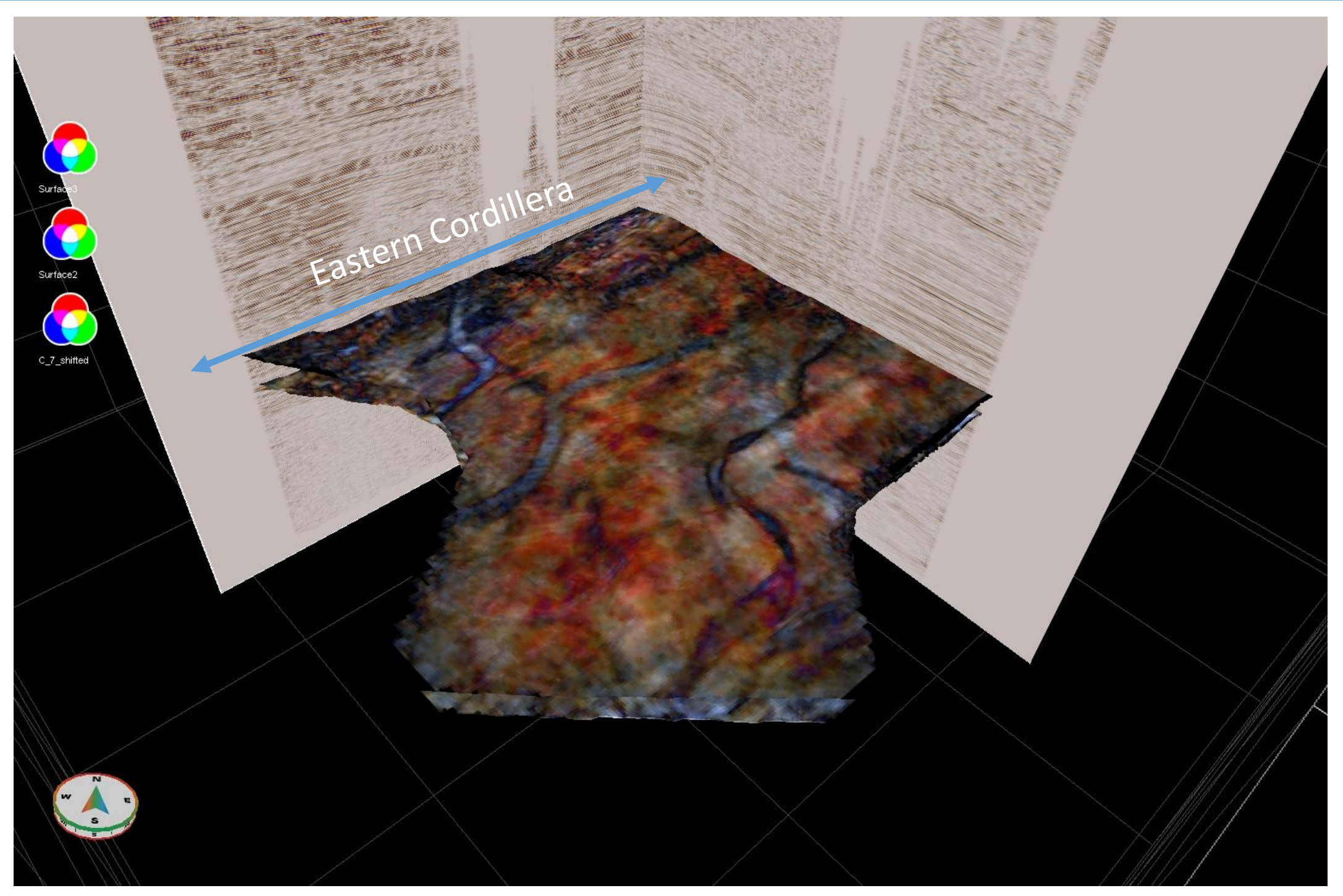




\section{Spectral Decomposition Expression of Tectonic Deformation}

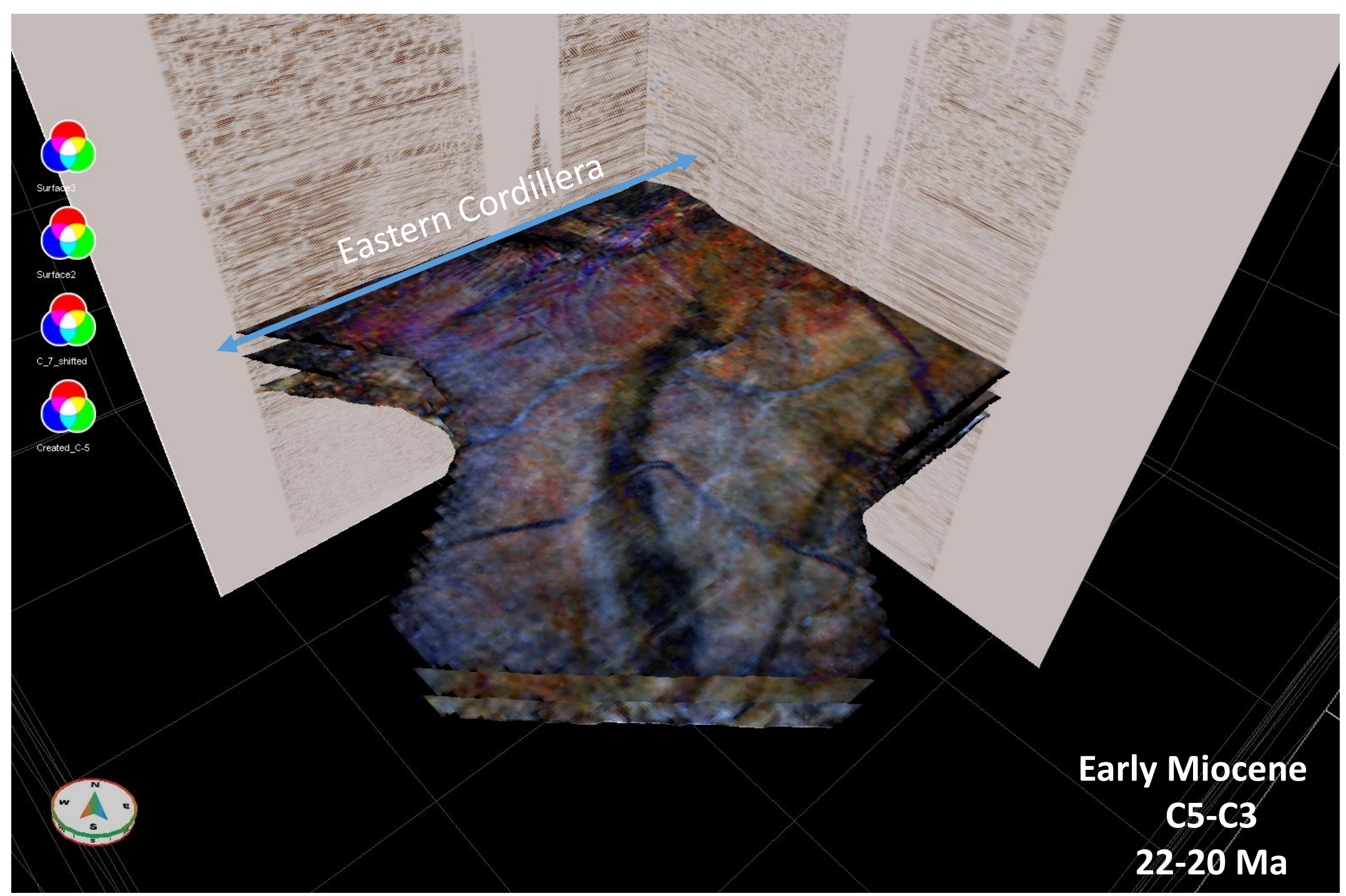




\section{Spectral Decomposition Expression of Tectonic Deformation}

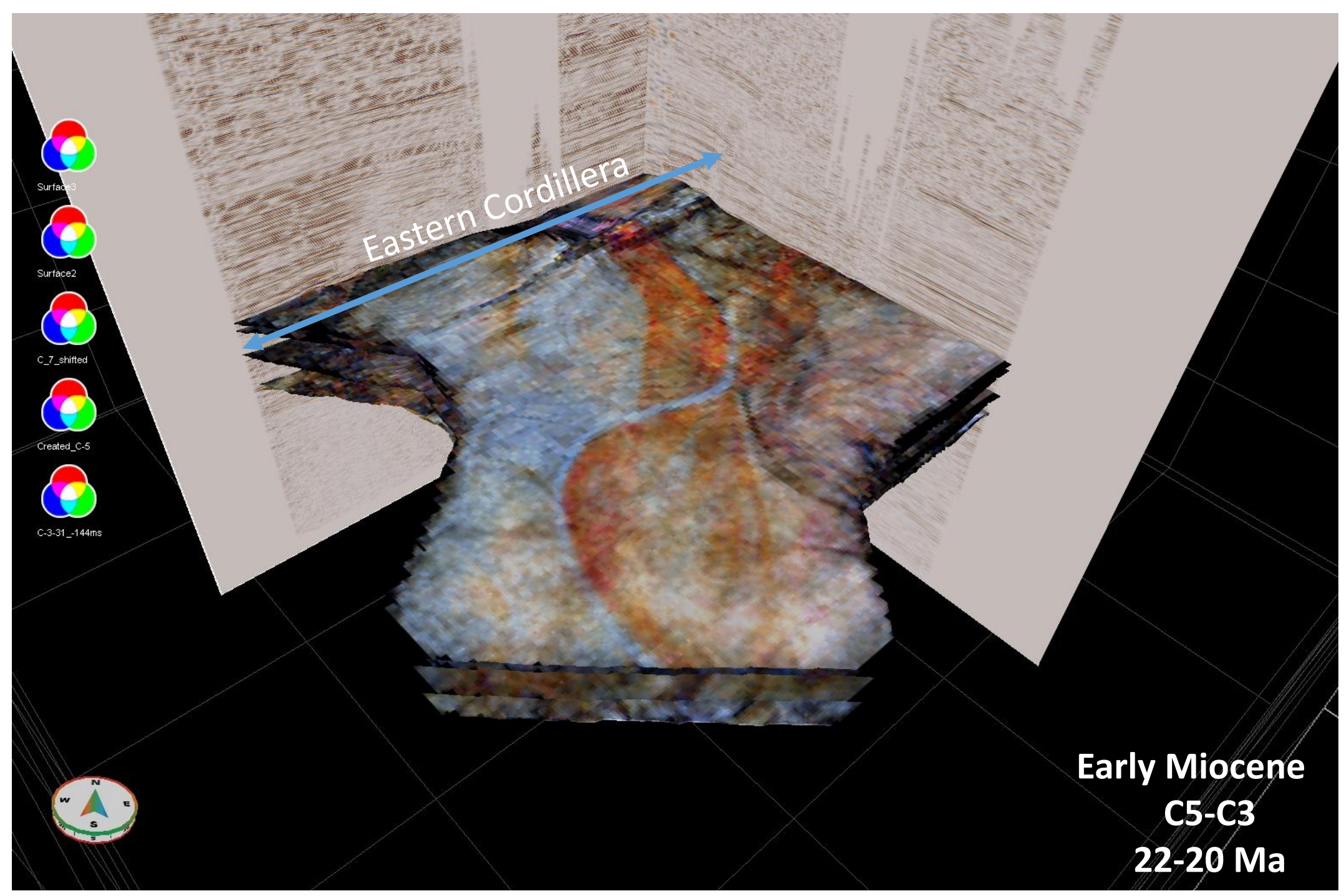




\section{structure and regional slope}

\section{B. Mature rift inversion}

\begin{tabular}{|l|l|}
\hline $\begin{array}{l}\text { high structural relief } \\
\text { steep regional slope }\end{array}$ & $\begin{array}{l}\text { longitudinal river } \\
\text { in active thrust sheet } \\
\text { or thrust-top basin }\end{array}$ \\
\hline
\end{tabular}

\section{transverse-dominated streams}

(slope-controlled)

remnant longitudinal catchment

being reduced by capture

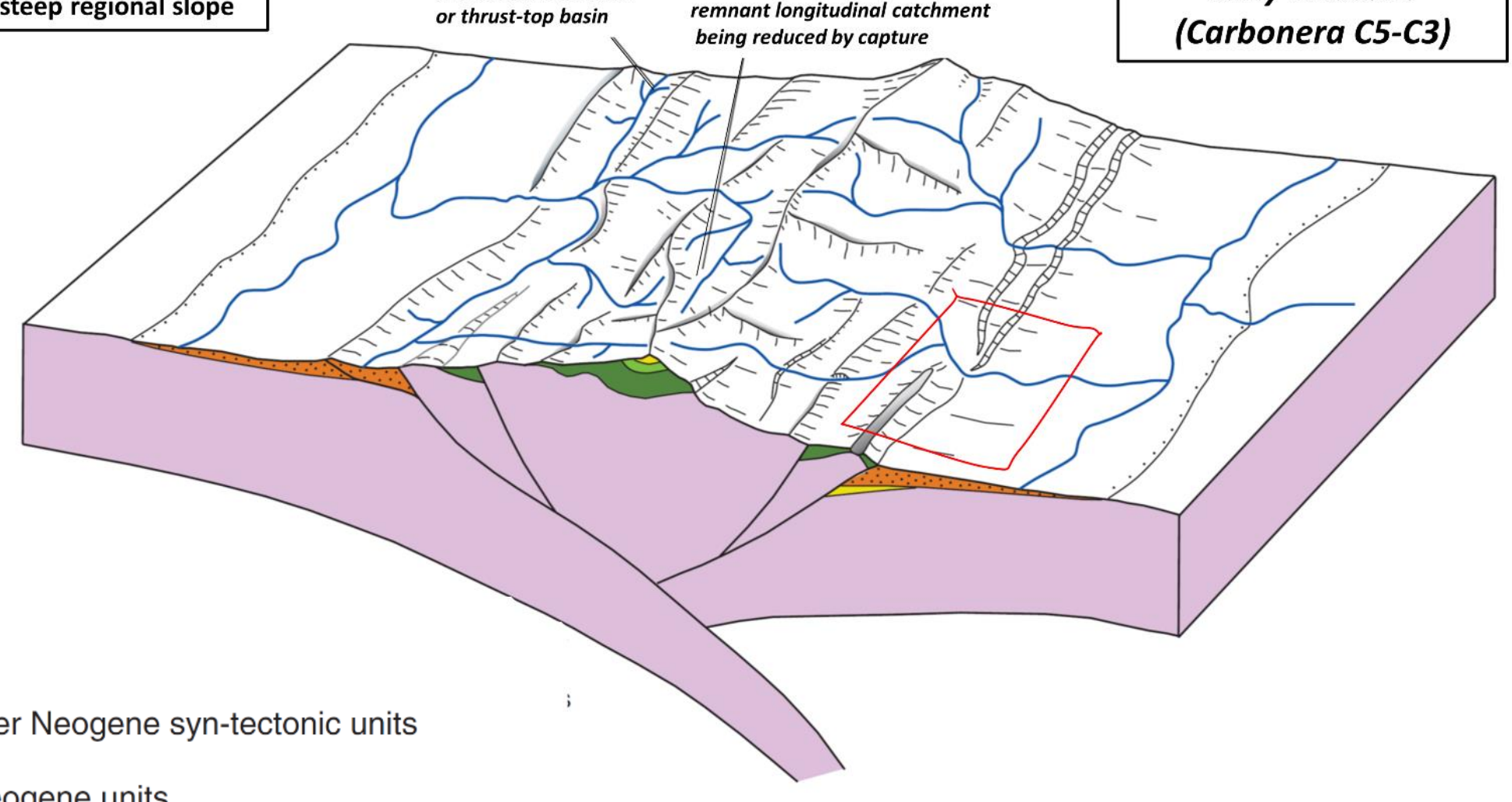

Paleogene units

Upper Cretaceous postrift units

Lower Cretaceous synrift units 
$>$ By using spectral decomposition we can detect subtle stratigraphic features undetectable in the time domain seismic data and correlate the sand bodies from well to well.

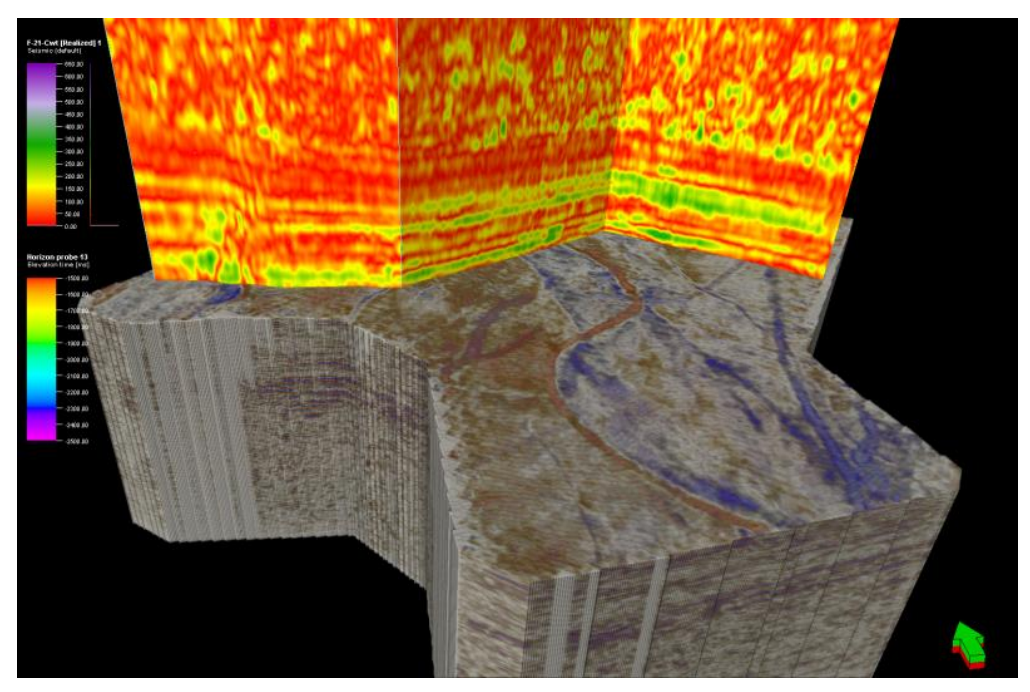

$>$ The integration of spectral decomposition and well character are powerful subsurface mapping techniques that make it possible, at last, to resolve the subsurface configuration of the Llanos Foothills of Colombia.

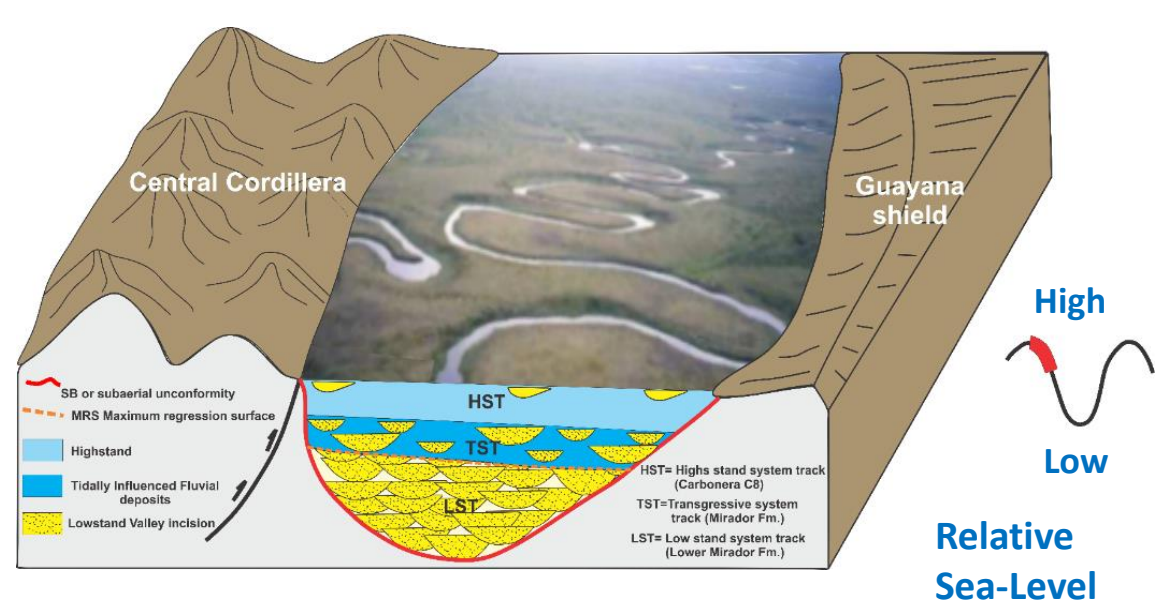




\section{ACKNOWLEDGEMENTS}
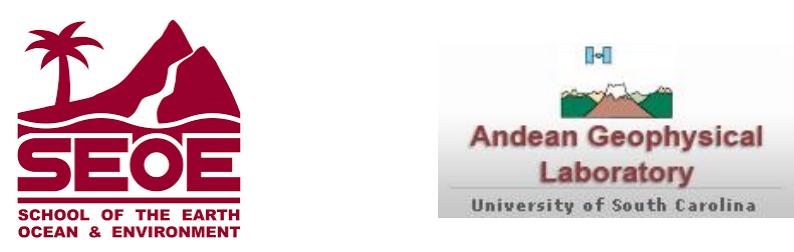

University of South Carolina

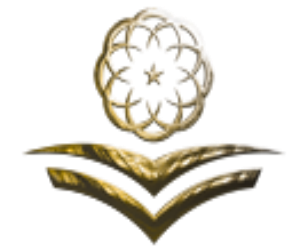

Ministry of High Education - Libya

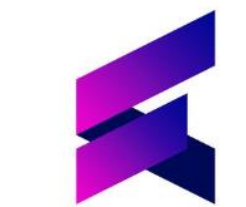

FRONTERA

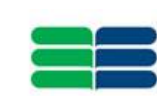

EMERALD ENERGY PIC

\section{0 \\ Teric
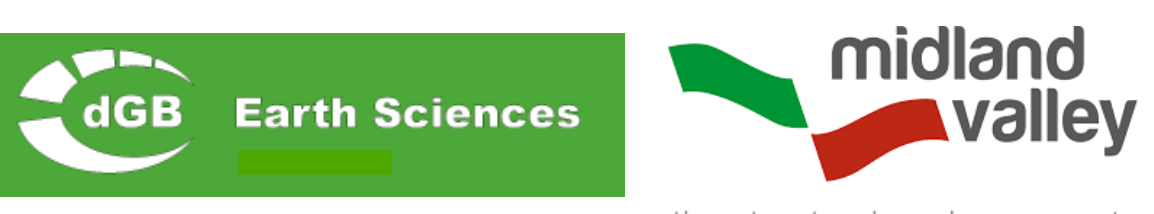

the structural geology experts

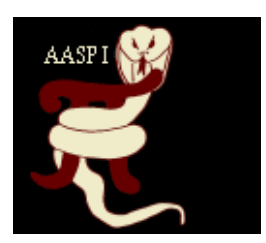

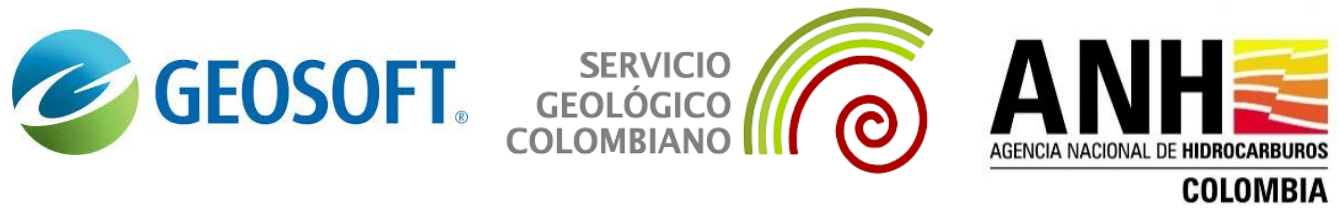
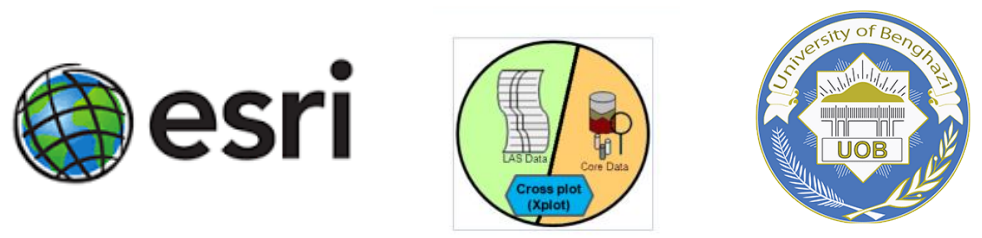
Thank You 